\title{
The Effect of Interlanguage and Arabic Verb System on Producing Present Perfect by EFL Learners
}

\author{
Mona Tahseldar, Soha Kanso, Yousra Sabra
}

\begin{abstract}
The acquisition of foreign language goes through many processes. One of these processes, which attempts to frame the impact of native language on foreign language, is Interlanguage. This study investigated the effect of Interlanguage and Arabic Verb System on producing Present Perfect by EFL learners. The participants of the study were Lebanese University undergraduates who had been studying EFL for 14 years. The erroneous, absence or unconventional usage of the present perfect motivated the researcher to inspect the reasons behind this production. The instrument of the study is four topics, addressing the present perfect temporal notion,was presented to the learners who chose two of them, and wrote a paragraph on each. The studied samples, which consisted of 100 paragraphs, belonged to 50 participants. Following quantitative and descriptive approach, the samples were collected, corrected, and data were analyzed using tables to demonstrate the percentages of proper usage of the present perfect and the verb forms that replaced it mistakenly. The results revealed that interlanguage is the reason behind the learners' wrong production of the present perfect form, as they produced their own systematic linguistic system, which mixed between their native Arabic language verb system and their English tenses in replacing erroneously the present perfect.

Index Terms - Interlanguage, present perfect, English tenses, Arabic language.
\end{abstract}

\section{INTRODUCTION}

Studying a foreign language is obligatory in Lebanon and starts at Kindergarten. This process of second language learning journey might encounter many hiccups in mastering the target language. The difficulties are innumerable whether in phonology, morphology, syntax, semantics, pragmatics, and so on, as noted by [32]. However, one of the most serious difficulties is expressing the temporal notion of the actions, for time is fluctuate; its concept to humans has evolved with time as it did to languages according to [41]. Therefore, each language has its different grammatical rules, notably tenses, aspects, or adverbials in order to specify, directly or indirectly, the timing notion of the utterance. Arabic and English, the languages involved in our study, focus on time temporal notion of verbs through both tenses and aspects, which makes it almost impossible to have a similar compatibility to all their forms. Accordingly, the perplexity, conflict, and difficulty of using verbs to the bilingual learner arise while trying to harmonize and assimilate internally the timing expressions and verbs in more than one language and

Mona Tahseldar, English Education, Associate Professor, Lebanese University

Soha Kanso, Ph.D candidate, Lebanese University

Yousra Sabra, English Education, Associate Professor, Lebanese University producing it according to the target language norms. A hypothesis that was presented by [49], which he coined as 'Interlanguage', explained the reason for such difficulty and erroneous production done by EFL students. Interlanguage can be briefly defined as the gradual evolving system of the second language learning of this journey from mother tongue (MT hereinafter) / native language (NL hereinafter) towards the foreign language / target language (TL hereinafter), namely learners' language development process. According to [49], learning a foreign language is affected by the influence of L1 on L2. Contrastive analysis bases language learning reveals that if L1 and L2 are of same origin then it might facilitate the process of acquiring the foreign language or otherwise it would effect it negatively. He also emphasizes that IL should not be seen by the lens of NL or by TL system, but as a separated linguistic system of its own, which conserve some features of the learners' NL on their way to become proficient or better in the TL. Thus, Interlanguage processes, characteristics, and variations provide insightful reasons for foreign language errors.

\section{A. Statement of the Problem}

The proper usage of the English tenses and aspects is considered as one of the stumbling blocks to the Arab learners as [33]. Accordingly, this is a persistent problem as noticed the researcher and her colleagues through students' productive EFL skills at the Lebanese University, Faculty of Sciences. One of the common mistakes is the present perfect. It forms a gap in the Lebanese learners' knowledge. The present perfect English verb form bridges the timing between the past and present. For that reason, its absence is crucial when expressing certain temporal notions, which are concerned with retrospective, existential, inclusive timing, and so on, for no other verb form in the English language can substitute it accurately. Therefore, the implication of this problem, academically, lies in producing improper timing of the verbs in the students' production. Thus, it prevents them from delivering their intended communication message clearly and accurately which is considered vital for any language production and teaching process. They replace, exclude, or even use it mistakenly. This conforms to many studies such as [37]. The present study hypothesizes that this problematic knowledge gap stems from the interlanguage due to the effect of Arabic language as the mother tongue on the English as the foreign language, conforming to many linguists, such as [57] who argued that learners' interlanguage mirrors a function-form correspondence with the learners' native language. 


\section{B . Purpose of the Study}

The purpose of this study was to inspect and present how the interlanguage hypothesis and the Arabic language grammatical verbal system affect the acquisition and employment of the English present perfect form by the Lebanese University undergraduates. It highlighted the causes of learners' erroneous production of the present perfect. It also demonstrated the problematic aspect in determining the temporal notion of which verb to use in their sentences, or in knowing the temporal notion but using simple tenses mostly as revealed in the usage of the adverbials of present perfect form but with simple tenses verbs or vice versa.

\section{B. Study Questions}

To figure out the correctness of the assumption behind this study, this research aimed at inspecting and answering these two research questions:

1- How is Interlanguage responsible for the inappropriate use of the present perfect form in the Lebanese University students' writings?

2- What is the subsequent effect of L1 grammar on the usage of the present perfect in the Lebanese University students' writings?

\section{Significance of the Study}

The present perfect is an important temporal notion that expresses certain timing of the action in the English language. This study is significant because it investigates the effect of L1 grammar on that of L2; which is demonstrated in an interlanguage - an unconventional employment of present perfect by Lebanese learners. Consequently, the teachers of EFL notably in the Arab worldwill gain insight and information about this gap in knowledge, shed light on the problem, raise awareness of its importance, and develop new perspectives and approaches of the potential reasons of erroneous usage of the other tenses and aspects. Aspiringly, this will also contribute in improving the learners' usage of the present perfect because highlighting the reasons of the problem is the crux of the solution. Overall, this study aims at contributing, even if as little as a drop in a bucket, in improving the quality of learning and education of EFL, for small contributions lead to significant changes.

\section{LITERATURE REVIEW}

Interlanguage hypothesis is one of the second language acquisition theories, which was coined by [49]. Onwards, it has been central to linguistic researches all over the world and has had major contributions in the SLA field. It reflects the exerted efforts of L2/FL learners in producing their own linguistic system while gradually approaching their target language [19]. The learners' errors committed while producing the foreign language are not always perceived as errors if seen through Interlanguage. The students build up their own phonological, syntactical and semantic usage rules. According to [17], the emergence of IL hypothesis verifies the alternations in psychological perspectives of L2 learning from a behaviorist approach to a mentalist one. Cognitive theories of IL, regarding grammar, hypothesize that learners build mental grammars of L2; that is, learners draw on the 'rule' they have acquired to infer and produce utterances. Moreover, meaningful performance situations are derived from learners' utterances in their native language (NL), IL utterances produced by the learner, and the TL utterances produced by native speakers of that TL [49]. These three factors are the psychologically relevant data of second language learning and form the umbrella that covers interlanguage. It is important to conduct studies on bilingualism because such inter-lingual identifications of phonology, grammatical relation and semantic features of these two languages are done by the learners themselves due to latent psychological structure (LPS hereinafter) [49]. There are five central psycholinguistic processes in the LPS, which are salient to IL and shape the learners' language [49]. The five central psycholinguistic processes are: 1) native language transfer; 2) overgeneralization of target language rules; 3) transfer of training; 4) strategies of communication; 5) strategies of learning. He states that these elements lead to fossilization or any of them might fossilize. Fossilization will not be discussed, for it does not serve the purpose or the academic profile of the participants in our study.

\section{A. Interlanguage First Process: Native Language Transfer}

The notion 'transfer' ranks as number one shaper of the IL [4]-[43]. The latter states that transfer is the influence resulting from similarity and differences between the target language and any other language that has been previously (and perhaps imperfectly) acquired. To pinpoint briefly transfer from the syntactical approach, Odlin [43] argues that L1 learners play a specific role in the configuration of their second language syntax. The process to spot transfer can be done in three steps: First, we observe the learner's productive interlanguage data, second it is based upon our definition of a transfer, and third we focus on the different methods that learners use in expressing and comprehending a speech in the TL [18]. Learners use their own observations and experience to develop informal theories and hypotheses [25]. The studyconducted by Diab [13] examined 73 English essays among Lebanese learners and the syntactical errors ranked first in her study. She attributed the result to 'transfer' between Arabic and English language. The conclusion relied on analyzing errors, counting them and comparing between Arabic and English structures. She disregarded the other effects as transfer of training, overgeneralization, and so on.

\section{- Types of Language Transfer}

Transfer is classified into positive and negative transfer [44]. Positive transfer occurs when two languages have similarities, which play positive role in acquiring TL. Meanwhile, negative transfer is the most important one, and it equals to errors due to their NL. Transfer is divided into underproduction, production, overproduction, and miscomprehension and other effects that constitute a divergence between the behavior of native and non-native 
speakers of a language [44]. An example is derived from literature regarding the negative effect of Arabic language in producing English sentences without 'verb to be'. In Arabic language as mentions [48], there is no copula of 'verb to be', so Arabic learners tend to omit 'verb to be' forms while producing English sentences. Here is an example to illustrate the idea.

الوزنُ ثقيل 1 The weight heavy ${ }^{1} / \mathrm{Al}$ Waznu Thakeel ${ }^{2}{ }^{3}$

In Arabic, it is just two words with no verb, while the correct English form is The weight is heavy. No correct English sentences can be composed without a verb.

\section{B. Interlanguage Second Process: Overgeneralization of Target Language Rules}

Reference [5] defines it as "a process that shows evidence of having mastered a general rule, but does not yet know all the exceptions to that rule." Moreover, reference[49] illustrates it with the following examples: What did he intended ${ }^{*}$ to say? ${ }^{4}$ The past tense morpheme ' $e d$ ' is extended to all the simple past usage without regarding the other rules or exceptions. Overgeneralization, according to [53],leads to a more inconvenient learning task by extending a language rule to linguistic norms where it is not appropriate, or where it would result in ungrammaticalities due to the false analogy with other forms. Students in higher levels produce more overgeneralization errors than those with lower levels[54]. Flick as cited in [15], did a study on 20 adult- Spanish learners of L2 English by an oral translation task. Five factors emerged from the analysis, which was criticized for being a very mixed bag. Yet, our interest lies in his statement that transfer accounted for 34 percent and overgeneralization for 16 percent. In other words, transfer and overgeneralization composed 50 percent of the reasons of errors. Transfer and overgeneralization are considered as the only responsible factors for errors [37].

\section{Interlanguage Third Process: Transfer of Training}

Reference [42] defines this process as "influences on the production or comprehension of a second language that are due to the ways learners have been taught (or to ways learners have taught themselves)." Furthermore, transfer of training is involved deeply in the educational process as cited in [53], including teachers, textbooks, and teaching aids, could be responsible for L2 erroneous utterances. He gives an example of a book or lesson plan that explains the past perfect as the "past past" can lead the learner to utter mistakenly and use it as the absolute distant past for all the actions that happened with him long time ago as My relatives had come from Italy in the 1700s. These errors are also called 'induced errors'. Reference [55] discusses another perspective of this process by focusing on the importance of input that serves the purpose of language acquisition in the learners' output. Trosborg, as

\footnotetext{
${ }^{1}$ This is the English word by word translation.

${ }^{2}$ This is the Arabic transliteration of the word

${ }^{3}$ This is the Arabic sentence.

${ }^{4}$ The correct structure is: What did he intend to say? due to the simple past rule which states that 'did' is always used with the infinitive form of the verb.
}

cited in [55], states that it is "the portion of L2 input which is assimilated and fed to the IL system."At that time, research by different scholars as cited in [55], supported the idea that acquisition was related to the structure and variability of the different forms and functions present in the input.

\section{Interlanguage Fourth Process: Strategies of Second Language Learning}

Learning strategies are the methods that learners draw on to learn a second language while trying consciously to master the TL. Tarone [53]indicates that learners have interlingual identifications when they aware of the comparison of their production between their NL and TL. For instance, according to [49], memorizing through flash cards and textbook dialogues might be confusing sometimes where the learner might use the word pot to memorize pato in Spanish which means duck, but might end up using pot for duck. He considers that learners use this process in order to "reduce the TL to a simpler system."

\section{E. Interlanguage Fifth Process: Strategies of Second Language Communication}

Tarone [53] defines this process by linking it to IL when he says: "strategies of communication are used by the learner to resolve communication problems when the interlanguage systems seem unequal to the task." He gives an example of the word cord, when the learner does not know its meaning, then he / she resorts to express it by saying a tube or kind of a tube that you use for electrical thing.According to [12], this communication strategy is used when things go wrong, and he describes it as "a spare tire for emergencies." The communication strategies used by learners may be an indication to their level of progress in acquiring L2 [14]. Learners speak their L1 fluently, but they cannot speak their L2 fluently, which results in a knowledge gap of their L2 [6]. These gaps can be a word, a phrase, a structure, or a tense marker.In Putri's study [46], the researcher lists the factors that affect the choice of the communication strategies as follows: learners' attitude, learners' level of L2 proficiency, learners' personality, learning situation, and communication context.

\section{F. Characteristics of Interlanguage}

The characteristics of IL are stability, systematicity, mutual intelligibility, and backsliding. Stability is the consistency for using a specific rule over time in the IL learning field. It occurs when L2 learners use the same form for two times and more. According to [50],stability is regarded as the occurrence of "certain errors and other surface form in learner-language systems."As to systematicity, IL is systematic because its rules or items are not random set of rules that are not identical to the TL rules; however, it has its own collection of rules [52]. Furthermore, L2 can be systematic when it shows internal consistency while using certain forms at a certain time [51].As stated in [2], mutual intelligibility is "linguistically regarded as a relationship 
between dialects or languages in which speakers of different languages can to some extent understand each other without extraordinary effort."He also considers mutual intelligibility as the inherent property of the IL that enables it to be a member of the human language. Reference [9] explains backsliding as mastering a certain linguistic form in the TL and afterwards it suffers from loss or no use or even misuse of that form. It is the constant appearance of forms or errors despite correcting them using explicit grammar or explanation, and even if they do not appear all the time, but they might be encountered in spontaneous production [15].

\section{G. Interlanguage and Syntax}

Interlanguage syntax is inspected when neither L1 nor L2 is responsible for the erroneous production. The differences between English and French are not responsible for errors production [60]. He clarifies that French learners of English never hear the 'SOV' word order while learning English; consequently, they rarely use their native language word 'SOV' word order while producing English. On the other hand, English learners of French frequently hear 'SOV' word order while learning the English language.

Interlanguage and syntax and in particular the verb system are the highlights of this research. Grammar is an integral part of syntax, and it is important to any language, notably to English and Arabic. In the following section we will encounter and discuss the L1 (Arabic) and L2 (English) grammatical verb system.

\section{H. English and Arabic Grammatical Verb System - Arabic Verb System}

Comrie [11] states, "In written Arabic, there are two sets of forms, traditionally referred to variously as aspects, tenses, or states, and distinguished either as Perfect and Imperfect, or as Perfective and Imperfective."According to [36], Arabic verb forms are regarded as only "tenuously concerned"with tense differences. The primary function of which is essentially aspectual, showing the distinctions between situations that have been realized or carried out and those which still have to be realized. They point out that the two-tense system of the Arabic verb embodies a realized/unrealized distinction rather than very clear temporal differences. Furthermore, Haded [24] argues that Arabic has two-way morphological divisions which have clear semantic functions. According to [30]-[29], there is the suffixal forms 'almādi' الماضي' ‘perfective' which denotes completed situations while the prefixal forms 'almudāri' المضارع 'imperfective' expresses the non-completed ones. Not all languages necessarily have same inflections to mark aspect, but they always have ways to express the meanings that are included in the aspectual categories [27].

Some might find these terms confusing and this is a natural feeling especially for second language learners of Arabic. According to [58], he refers to the perplexity of these terms and integration by saying

A Semitic perfect or imperfect has, in and of itself, no reference to the temporal relations of the speaker (thinker or
writer)....The Arab grammarians themselves have not, however, succeeded in keeping this important point distinctly in view, but have given an undue importance to the idea of time, in connection with the verbal forms, by their division of it into the past (الماضي), the present ( الحال او الحاضر), and the future (المستقبل), the first of which they assign to the Perfect' and the other two to the Imperfect.

\section{- English Language Verb System}

Regarding English language tenses, some linguists, such as [59], consider that 'tense' is limited to simple present and simple pastwith some rare claims that it also includes simple future. English as an aspect language, according to [59], has two aspects and can be expressed grammatically, "via the perfect and progressive forms of the verb." According to [11], the grammatical differentiation is the mark of verb to be+ present participle as in $I$ am eating which are called progressive verbs, and verb to have + past participle as in $I$ have eaten which are called perfect verbs. Reference[22] point to the fact that "the progressive or (continuous) focuses on the situation as being in progress at a particular time", explaining that "verbs with stative senses do not occur in the progressive, since there is no conception of progression in states of affairs." The progressive aspect has different meanings such as continued action, dynamic action, and durative action. Salaberry and Shirai, as cited in [41], adopt the above explanation, but add to it the 'neutral view' when the event or action is flexible.

\section{Present Perfect Form}

According to [20], the present perfect is a phase or relative tense which places the state or event chronologically before another or before a specific point in time. Moreover,Leech[31] considers it as mainly used to refer to past time that has present relevance, and its states and events are invariably indefinite. It is also characterized with "continuance of states to the present and the present result of event verbs."As indicated in [41], it is suggested that the present perfect connects the past to the present in two ways. It can be 'retrospective', which focuses on the present state and considers it as a result of previous incidents in the past for example,Ahmed does not want to eat now because he has already eaten.It can also be "inclusive", and the verb in this case extends from the past to the present timing, for example, He has lived in Dubai for the last two years. However, [35] expands these structures and divides the present state of affairs into 'three distinct implications'. The first case is the "resultative" where the results of the finished situation are still relevant to the present as in the previous Ahmed's previous example wherea dinner invitation is addressed to Ahmed, but he does not want to come because he has already eaten. Ahmed's present action of refusing the invitation is a result of something that has already happened with him previously which is the eating. This one is similar to the retrospective structure. The second case is the "existential" in which the situation is repeated within certain duration of time as illustrated in thisexample. Harry has visited us twice this week. Harry here has repeated the same action two times 
within one week. The third case is the "continuative". The action is still in progress, may have just finished, or may continue. Reference [20] further explains it that it might be in broken manner, habitual, or repeated. This implication resembles the inclusive one.Semantically, [34] indicates that present perfect consists of present and past abstract predicates; however, the present one controls the past one. It is a compound verb form that applies to states and events presenting two structures. The first one consists of: the auxiliary verb to have + past participle of a stative verb + optional durative adverbial, forming the surface structure of the present perfect state as John has lived in Washington since 1970, as mentioned in [41], or the second structure starts with: the auxiliary verb to have + past participle of an event verb + optional adverbial, forming the surface structure of the present perfect events such as I have already written a letter, [29]. In this case, the adverbials are optional and not durative, such as already, just, yet, ever, and never. The durative adverbials are not always appropriate with the event present perfect since the action has not extended over a period of time.

\section{J.Present Perfect in English and Arabic}

According to [28], there is no morphological set of forms in Arabic.Thisabsence of a corresponding present perfect form in the LI, according to [38], isundoubtedly significant in the difficulties encountered by learners in masteringthis form.Nevertheless, Kharma and Hajjaj [30] consider that Arabic language system embeds the present perfect tense conceptually, but it is not similar to the English present perfect. They state that "the categorical grammatical meanings expressed by the continuous and perfect forms in English cannot be easily associated with clear cut expanded forms in Arabic". This will be revealed in Tables I and II. The reference [1] believes that any two languages have different grammatical patterns in order to determine certain aspects of temporal notion.

-wasal/- وصَلَ /-'he arrived' and 'he has arrived' [41]

Accordingly, reference [3] presents 'Functional Equivalence between Tense and Aspect in English and Arabic'. The examples in Table I, adopted partiallyfrom [3], where the explanation and categorization are done by the researcher, in order to show how present perfect is used in each one of the three demonstrations. In [a], it was replaced with simple present; in [b], it replaced mistakenly the simple past as in [c] with the recent past.

Table I: Functional equivalence between tense and aspect in English and Arabic

\begin{tabular}{|c|c|c|c|c|}
\hline Duration/Tense & $\begin{array}{l}\text { Arabic } \\
\text { Transliteration }\end{array}$ & $\begin{array}{l}\text { Arabic } \\
\text { Standard } \\
\text { Writing }\end{array}$ & $\begin{array}{l}\text { Erroneous } \\
\text { Translation } \\
\text { of the Arabic }\end{array}$ & $\begin{array}{l}\text { Correct } \\
\text { Usage }\end{array}$ \\
\hline $\begin{array}{l}\text { [a]Simple } \\
\text { present }\end{array}$ & $\begin{array}{l}\text { arifuha } \\
\text { mundu } \\
\text { sanwawātin }\end{array}$ & سنواتٍ & $\begin{array}{l}\text { I know her } \\
\text { for years }\end{array}$ & $\begin{array}{l}\text { I have } \\
\text { known } \\
\text { her for } \\
\text { years }\end{array}$ \\
\hline [b]Simple Past & $\begin{array}{l}\text { mundu 'an } \\
\text { kābaltuhu }\end{array}$ & منذ ان قابلتنهُ & $\begin{array}{lr}\begin{array}{l}\text { Since } \\
\text { have } \\
\text { him }\end{array} & \text { met } \\
\end{array}$ & $\begin{array}{l}\text { Since I } \\
\text { met } \\
\text { him. }\end{array}$ \\
\hline [c] Recent Past & $\begin{array}{l}\text { qad wajada } \\
\text { hallan }\end{array}$ & قد وجد حلاً & $\begin{array}{l}\text { He found a } \\
\text { solution }\end{array}$ & $\begin{array}{l}\mathrm{He} \text { has } \\
\text { found a } \\
\text { solution }\end{array}$ \\
\hline
\end{tabular}

Table II: Present perfect and its equivalent forms in Arabic

\begin{tabular}{|c|c|}
\hline $\begin{array}{l}\text { Present Perfect / } \\
\text { English }\end{array}$ & Arabic Translation \\
\hline $\begin{array}{l}\text { [d].current } \\
\text { relevance of a past } \\
\text { situation } \\
\text { (resultative) } \\
\text { (Depraetere and } \\
\text { Reed, 2000) } \\
\text { She has written this } \\
\text { letter }\end{array}$ & $\begin{array}{l}\text { active participle or perfective } \\
\text { /hiya katiba halmaktub . ([29] } \\
\text { هي كتبت هذا المكتوب }\end{array}$ \\
\hline $\begin{array}{l}{[\mathrm{e}] . \quad \text { existential }} \\
\text { situations } \\
\text { I have visited } \\
\text { Egypt three times }\end{array}$ & 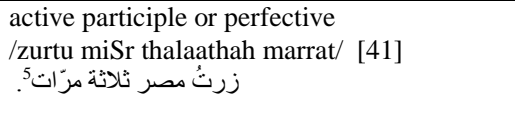 \\
\hline $\begin{array}{l}{[\mathrm{f}] \text {. continuative }} \\
\text { situations } \\
\text { I have worked in } \\
\text { this company for } \\
\text { six years } \\
\text { I have been } \\
\text { working in this } \\
\text { company for six } \\
\text { years. }\end{array}$ & 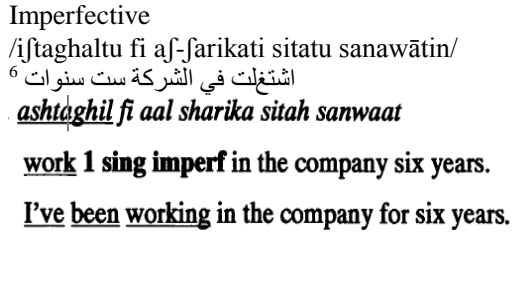 \\
\hline
\end{tabular}

It is to be noted that according to [28], the Arabic article 'qad' or 'laqad' denotes modality or tense and aspect when placed before the perfect, and it has 'time-related' functions. [23] adds that 'qad' or 'laqad' can be combined with 'kāna' and the perfect form refers to an action/event. Tables I and II posit that there is no one-to-one relationship between English present perfect and Arabic Verbs. The present perfect is expressed by both perfective and imperfective of Arabic language. The terms of perfective, imperfective, tense andaspect are unfortunately overlapping between these two languages.

\section{RESEARCH METHODOLOGY}

This study is quantitative and descriptive in nature for its aptness for timing, data presentation, and analysis. Quantitative method provides a significant connection between test and statistical analysis. This method allows involving a larger number of samples and strengthens the generalizations of the result. The quantitative method employed conforms to the definition presented by [4], who posit that the quantitative nature of the content analysis involves, in its simplest forms, 'counting concepts, words, or occurrences in documents and reporting them in tabular form.' In addition, it decreases the variables and, most importantly, the applicability of the replication of the study. The descriptive approach allows the analysis and interpretation of these descriptions as indicated by [10]. The descriptive function of research is heavily dependent on instrumentation for measurement and observation, and it provides a clear and precise description, according to [7].

\footnotetext{
ثلاثة مرَات5 means three times and this what changed the verb form from simple past to the present perfect which equals existential present perfect; otherwise, it would have been the same to Example [d].

${ }^{6}$ The picture is placed under Arabic transliteration in order to present the validity of copying from the resource; however, the researcher believes that this example is wrong and the word 'munzo' ن which means 'for + duration' or 'since+duration' in English, should be added to convey correct meaning. Otherwise, the sentence must be expressed in the simple past or past perfect since the Arabic verb is in the perfective form.
} 
Moreover, descriptive studies can acquiesce rich data which outcomes important recommendations. It enables the researcher to present the statistical data through percentages demonstrated in pie graphs, bars, and so on.

\section{- A. Participants and Population}

The participants are 50 undergraduates, 4 males and 46 females ranging between 19 and 21 years old. They are all Lebanese with a homogeneous background. It is to be noted that this population is also the accessible population, so the external validity of sampling is accomplished, according to [7] who consider that the greater the link between sample, accessible population and target population the more valid generalization can be done. All students at the Lebanese University at the faculty of Sciences but of different majors (Chemistry, Biology, Physics, Mathematics, and so on)enrolled in the second year. They receive60 hours of EFL throughout one academic year, three hours per week for twenty weeks.

\section{- B. Instrument}

In order to test the participants' employment of the present perfect in written production, the instrument of the study is the corpus produced from the targeted written composition. These instruments are valid and reliable for their commonality in ILELTS, SAT and TOFEL exams. Assessing students' production can only be done by presenting topics to the students that simulate the temporal notion of the intended verb form to be assessed. The students were asked to choose two out of four topics. Three of the four topics are in question forms and one is a statement, all using the present perfect form and adverbs/adverbial indicator. Three of these topics use present perfect adverb so far and one used since. The questions that students were asked to respond to are:

Q1:Every person goes after having his parents proud of him/her. State what you have practiced, studied, and achieved so far to make your parents proud of you.

Q2: What are the significant experiences that you have undergone throughout your life so far that have affected your personality and made you who you are now?

Q3: Have you ever dreamed of being an athletic person/ a top model/ an inventor/ an adventurer/ a teacher/ a doctor/ an actor, etc.? What have you done so far in order to achieve your dream?

Q4: What are the professional/work options that you have tried since you became 18 years old in order to improve your financial status and be a financially independent person?

\section{Procedures}

After a pilot study, the researcher addressed the study four topics that clearly relate past to present and phrased all the questions and statements in the present perfect form with present perfect adverb/ adverbials. The researcher also related the topics to the participants' personal, financial, and academic experiences to draw their interests. The researcher assigned the sessions and dates to do the writing. It was not accessible to do the writing in one timing. Thus, the process of distributing the samples and collecting them lasted two days. The invigilators distributed the papers to the participants and encouraged them to take the task seriously because it is a part of study without enclosing any further information of its purpose fearing that they might write present perfect haphazardly. Each participant was asked to choose two out of the four writing questions and answer each of them in a paragraph of not less than 7 lines. The allotted time was 35 minutes purely for writing. Many of the 104 collected papers were disregarded due to various reasons such as unreadable handwriting, and so on. Later on, only 74 formed a source of data for the study of which 50 papers were randomly chosen. For an effective correction, the researcher set list of abbreviations in order to present the categories of correction; for instance, PPP indicates to the present perfect verbs properly used in the paragraphs as shown below in Table III. Each erroneous category was filled in with ' $\mathrm{x}$ ' based upon the numbers of the verbs, while each $\sqrt{ }$ indicated to the number of the present perfect proper use. Each correct or erroneous usage was counted as one number as shown in Table IV. In view of the fact that, the researcher is not a native speaker and correction errors might occur, another native colleague did the second correction, and from an American-Lebanese friend who is an English teacher as well, for a third correction. The common mistakes in the threephase correction were adopted. The erroneous or proper usage of present perfect form was counted in all the 50 papers equals to 100 paragraphs. The counting of these errors was manual and these numbers were filled in an excel chart in order to produce statistical data and reach conclusions through pie graphs. The produced percentages are calculated using

http://www.had2know.com/education/pie-chart-percentagescalculator.html. These percentages were enlisted again in an excel sheet in order to produce the statistical data in tables and percentages in order to inspect and deduce the answers for the hypotheses of this study. Other errors as spelling, subject-verb agreement, irregular simple past, and wrong form of simple past or past participle are encountered, but not given any records due to their irrelevance to the study.

\section{- Statistical Presentation of Students' Production}

The researcher collected the samples, corrected them, and classified them into categories, PPP+AD, PPP-AD, SP\#PP, SP\#PPAD, SPR\#PP, and SPR\#PPADto present the proper use of the present perfect, in addition to its unconventional substitution by other verb forms. Each correct or erroneous usage was counted as one number.

Table III: Codes and Definitions of the correction and statistical results

\begin{tabular}{|c|c|}
\hline Code & Definition \\
\hline PPP+AD & $\begin{array}{c}\text { using present perfect in the presence of a } \\
\text { time expression denoting the present perfect }\end{array}$ \\
\hline PPP-AD & $\begin{array}{c}\text { using present perfect in the absence of a } \\
\text { time expression denoting the present perfect }\end{array}$ \\
\hline
\end{tabular}




\begin{tabular}{|c|l|}
\hline SP\#PPA & $\begin{array}{l}\text { using simple past tense instead of the } \\
\text { present perfect in the presence of a time } \\
\text { expression denoting the present perfect }\end{array}$ \\
\hline SP\#PP & $\begin{array}{l}\text { using simple past instead of present perfect } \\
\text { in the absence of a time expression denoting } \\
\text { the present perfect }\end{array}$ \\
\hline SPR\#PP & $\begin{array}{l}\text { using simple present instead of the present } \\
\text { perfect in the presence of a time expression } \\
\text { denoting the present perfect }\end{array}$ \\
\hline SPR\#PP & $\begin{array}{l}\text { using simple present instead of present } \\
\text { perfect in the absence of a time expression } \\
\text { denoting the present perfect }\end{array}$ \\
\hline
\end{tabular}

The total of each category was recorded in an excel sheet. In order to derive percentages, these totals were enlisted manually in the website: http://www.had2know.com/education/pie-chartpercentagescalculator.html,which generated the percentage results. These percentages were enlisted again in an excel sheet in order to produce the statistical data in pie graphs in order to inspect and deduce the answers for the hypotheses of this study.

Table IV: Number and Percentages of the verbs in each category

\begin{tabular}{|l|c|l|}
\hline Code & $\begin{array}{c}\text { Number of } \\
\text { verbs/ 188 }\end{array}$ & Percentage \% \\
\hline PPP+AD & 4 & 2.13 \\
\hline PPP-AD & 29 & 15.43 \\
\hline SP\#PPAD & 27 & 14.36 \\
\hline SP\#PP & 79 & 42.02 \\
\hline SPR\#PPAD & 13 & 6.91 \\
\hline SPR\#PP & 36 & 19.15 \\
\hline
\end{tabular}

Table IV demonstrates consecutively the numbers and percentages of the data and gives comprehensive image of our obtained results. Out of 188 verbs, 79 verbs are in the simple past form, substituting the present perfect without the presence of any present perfect adverbs. That is, the percentage of SP\#PP equals $42.02 \%$. Examples 3, 4 and 5 represent a sample of students' erroneous production of this area:

3- I entered* the university and studied chemistry and now I am planning to have Master's degree. ${ }^{7}$

4- From what happened to us, our life changed* and we achieved* many goals. ${ }^{8}$

5- I was* always number one until now. ${ }^{9}$

The verbs in the simple past tense that substitute the present perfect in spite of the presence of adverbs or adverbial clauses of the present perfect SP\#PPAD counted 27 and rated $14.36 \%$. That is, the simple past tense was used by the

\footnotetext{
${ }^{7}$ I have entered the university and studied chemistry and now I am planning to have my Master's degree.

${ }^{8}$ From what happened to us, our life has changed, and we have achieved many goals.

${ }^{9} \mathrm{I}$ have always been number one till now.
}

students despite the presence of expressions like since as demonstrated in Examples 6 and 7.

6- Being a teacher was*my dream since I was a kid ${ }^{10}$

7- Since then, from that time till today*, I worked hard to train myself on being a teacher. ${ }^{11}$

Students even used the simple present tense without the presence of any present perfect adverbs/adverbials, SPR\#PP, instead of the present perfect in 36 verbs which equals to $19.15 \%$ as shown in example 8 .

8- I take* a decision to be brave and continue* studying and learning in order to have a job even if it is not an important one. ${ }^{12}$

Example 8 necessitates the use of have taken instead of take to convey the idea of continuity.

Moreover, the simple present tense is used in the presence of present perfect adverbs / adverbials, SPR\#PPAD, instead of the present perfect by 13 verbs with $6.91 \%$. That is, in the presence of since, students used the simple present as presented in Example 9.

9- Since that moment, I decide to be a great individual. ${ }^{13}$

However, 29 verbs in the present perfect were properly used in the 100 paragraphs without present perfect adverbs/adverbials, PPP-AD, which equals to $15.43 \%$. An illustration of this use is Example 10. The use of the present perfect in the presence of the present perfect adverbs/adverbials ${ }^{14}, \mathrm{PPP}+\mathrm{AD}$, is in 4 verbs which equals to

2.13\%. This continuity is demonstrated in Example 11.

[10] I have done many things to make my mother feel proud of me.

[11] I have dreamed of being a doctor since I was 12 years old.

Table V. Number of miscellaneous verb forms

\begin{tabular}{|c|c|c|}
\hline $\begin{array}{c}\text { Verb form and } \\
\text { category }\end{array}$ & $\begin{array}{c}\text { Number of } \\
\text { verbs /192 }\end{array}$ & Percentag \\
\hline Past perfect & 1 & $0.52 \%$ \\
\hline $\begin{array}{c}\text { Present perfect } \\
\text { continuous }\end{array}$ & 2 & $1.04 \%$ \\
\hline Unknown & 1 & $0.52 \%$ \\
\hline
\end{tabular}

Out of 192 verb forms encountered between proper usage and erroneous replacement of the present perfect, there were 4 forms of verbs, other than tenses, that replaced mistakenly the present perfect as demonstrated in Table V. There wasone form of this past perfect could be also attributed to wrong usage of 'verb to have' and disregarded from the study, and even if considered as a present perfect replacement, it scored

\footnotetext{
${ }^{10}$ Being a teacher has always been my dream since I was a kid.

${ }^{11}$ Since then, I have worked hard to train myself to become a teacher.

${ }^{12}$ I have taken a decision to be brave and continue studying and learning in order to have a job even if it is not an important one.

${ }^{13}$ From that moment, I have decided to be a great individual.

14 The term adverbs or adverbials are used simultaneously to refer to the temporal notion of the present perfect adverbs or adverbials
} 
$0.52 \%$. In addition to 2 wrong usages of the present perfect continuous replacing present perfect which score $1.04 \%$, and 1 usage of a verb that could not be honestly classified 'should be used to have been gone' equals $0.52 \%$. These 4 forms of verbs were disregarded from the study for their inconsequentiality, and their percentage ranked between 0.5 and 1 percent, which do not form any significance compared to the dominance of simple past and simple present. Table $\mathrm{V}$ presents these mistakes and their percentages.

Table VI: Percentage of simplepast, simple present and present perfect

\begin{tabular}{|l|l|}
\hline Code & Percentage \\
\hline PPP & $17.56 \%$ \\
\hline SP & $56.38 \%$ \\
\hline SPR & 26.06 \\
\hline
\end{tabular}

Rates of the 3 Verbs in General

Table VI shows that the simple past SP formed the biggest ratio in replacing the present perfect by $56.38 \%$ and the second slice of the present perfect went to the simple present (SPR) by $26.06 \%$, while the proper use of the present perfect PP rated only $17.56 \%$, which was less than the two tenses.

Table VII: Dominance without present perfect adverb/adverbial

\begin{tabular}{|l|l|}
\hline Code & Percentage \\
\hline PPP-AD & 20.14 \\
\hline SP\#PP & 54.86 \\
\hline SPR\#PP & $25 \%$ \\
\hline
\end{tabular}

Rates of the Categories not linked to adverb

Table VII shows the percentage of verb forms disregarding the categories of adverbials as SPR\#PP, PP\#PP and PPP-AD. However, we obtained the same gradual dominance where simple past ranked first with $54.86 \%$, simple present ranked second with $25 \%$ and the present perfect ranked the last with $20.14 \%$.

Table VIII: Dominance with Present Perfect

\begin{tabular}{|l|l|}
\hline Code & Percentage \\
\hline PPP+AD & 9.09 \\
\hline SP\#PPAD & 61.36 \\
\hline SPR\#PPAD & 29.55 \\
\hline
\end{tabular}

Adverbs/adverbials

Rates of verbs dominance with adverbs

Table VIII presents the percentage of using the simple tenses in spite of the presence of present perfect adverbs/adverbials. The simple past usage ranked first by $61.36 \%$, simple present ranked second with $29.55 \%$, while the present perfect itself ranked third with only $9.09 \%$.

Table IX: Verbs combined with and without adverbs

\begin{tabular}{|l|l|}
\hline Code & Percentage \\
\hline AD & 23.40 \\
\hline NAD & 76.60 \\
\hline
\end{tabular}

Adverbial Vs No Adverbial

Table IX presents the percentage of the verbs linked to adverbs/adverbials (AD). This percentage had not exceeded $23.40 \%$, while verbs dependence on temporal notions (NAD) rated $76.60 \%$.

Table X: Tenses Vs Present Perfect

\begin{tabular}{|l|l|}
\hline Code & Percentage \\
\hline Present Perfect & 17.56 \\
\hline $\begin{array}{c}\text { Simple Past }+ \text { Simple } \\
\text { present }\end{array}$ & 82.44 \\
\hline
\end{tabular}

\section{Tenses VersusPresent Perfect}

Table $\mathrm{X}$ is considered a summary of the unconventional use of the present perfect PP. It shows the combined percentage of the erroneous use of the simple present and the simple past compared to proper use of PP form in the 50 papers/100 paragraphs. As we see that tenses dominated using PP by a difference of $64.88 \%$ where tenses replacement of aspect recorded $82.44 \%$ and $\mathrm{PP}$ aspect proper use recorded only $17.56 \%$.

Table XI: Use of Present Perfect Vs Absence of Present

\begin{tabular}{|l|l|}
\hline Code & Percentage \\
\hline Present Perfect Use & $40 \%$ \\
\hline Absence of Present Perfect & $60 \%$ \\
\hline
\end{tabular}

Present Perfect Versus Absence of Present Perfect

Table XI shows the weak presence of the present perfect form in 100 paragraphs produced in 50 papers. The researcher considered that even the existence of one single present perfect form in the LUS paper as 1 indicator; 30 papers out of 50 did not include even one present perfect form which equals $60 \%$. Consequently, the $40 \%$ was the percentage of using the present perfect in 50 papers.

Table XII: Present perfect use with and without adverbials.

\begin{tabular}{|l|l|}
\hline Code & Percentage \\
\hline PPP+AD & 12.12 \\
\hline PPP-AD & 87.88 \\
\hline
\end{tabular}

Present perfect with Adverbs Vs using present perfect without adverbs

Table XII indicates to the difference between the proper use of the present perfect with and without adverbs/adverbials. Using proper present perfect without adverbials rated $87.88 \%$, whereas, present perfect with its adverbs/adverbials rated only $12.12 \%$.

Table XIII: Simple past versus simple present

\begin{tabular}{|l|c|}
\hline Code & Percentage \\
\hline Simple past & 68.39 \\
\hline Simple present & 31.61 \\
\hline Simple Past Vs Simple Present
\end{tabular}

Table XIII presents the dominance of the simple past against simple present substitution of present perfect, for 
simple past rated $68.39 \%$ of the erroneous replacement of the present perfect while simple present rated $31.61 \%$.

Table XIV: Simple past replacing present perfect

\begin{tabular}{|l|l|}
\hline Code & Percentage \\
\hline Simple past & 76.26 \\
\hline Present Perfect & 23.74 \\
\hline
\end{tabular}

Simple Past Vs Present Perfect

Table XIV demonstrates the simple past compared to the present perfect, where it replaced the present perfect by 76.2

\section{DISCUSSION OF THE STATISTICAL DATA}

Tables IV, VI, and X demonstrate that the proper usage of the present perfect does not exceed $17.56 \%$. The rate of its absence, as shown in TableXI, scored $60 \%$ in the writings of the Lebanese University students, LUS. The present perfect usage had to be probable due to the temporal notions of the topics relating past to present in different present perfect PP forms: resultative, existential, and continuative. In addition to the clear presence of the present perfect adverbials in the instrument's questions. The average usage of the present perfect in the 100 paragraphs is 1.8 if we divided all the 188 verbs over the 100 paragraphs produced, and in the 40 paragraphs which represent the 20 papers that included the present perfect it equals to an average of 4.7 present perfect verbs per paper which means 2.35 per paragraph, while the actual rate of used present perfect is 0.8 per paragraph with a difference of 1.55. Moreover, TableXIserves as a solid proof because a discussion of the validity of the correction might be addressed in any of the above percentages and data. However, the absence of the present perfect by $60 \%$ can be recorded without any margin of any sort of errors attributed to the correction process. Therefore, these graphs and percentages are indicators that LUS have problems in using the PP form. The surprising and unexpected finding regarding PP is represented in tablesIV, VIII, and XII where the proper usage of the present perfect used with its adverbials rated only $12.12 \%$ of the total of the proper usage of the present perfect while using present perfect properly due to its temporal notion rated $87.88 \%$, and it rated $2.13 \%$ compared to the other verbs. Shockingly, the simple past is the one used with the present perfect adverbials more than present perfect itself by a difference of $52.27 \%$ as shown in table VIII. Therefore, it is concluded that students do not master or rely on the adverbials of the present perfect form when using it, and they even mix it with other verb forms. The participants encountered noteworthy difficulty in employing present perfect. What is the hypothetical reason for this difficulty which produced a mixed bag of results between tenses and PP?On one hand, the dominating tenses are the simple past by $56.38 \%$, which is attributed to 'almādi' and classified as perfective in Arabic, and the simple present $26.06 \%$ which denotes 'almudari' and classified as imperfective in Arabic. The imperfective and perfective are the only two classifications of the Arabic language verbs unlike English which has 12 verb forms and many classifications, as explicitly revealed in the Literature Review. On the other hand, we have the present perfect form that is known to link the past to the present temporal notions The participants' erroneous usage of present perfect was limited to substituting it with either the simple past or the simple present.

This study assumes that interlanguage is responsible for this mixed bag production exemplified in some of the participants' production. Figure [1] in addition to inspecting interlanguage five psycholinguistic processes and characteristics aim at concluding the answer to the above mentioned research question.

Figure [1] presents the interlanguage responsibility where LUS amalgamated their L1 with their L2.

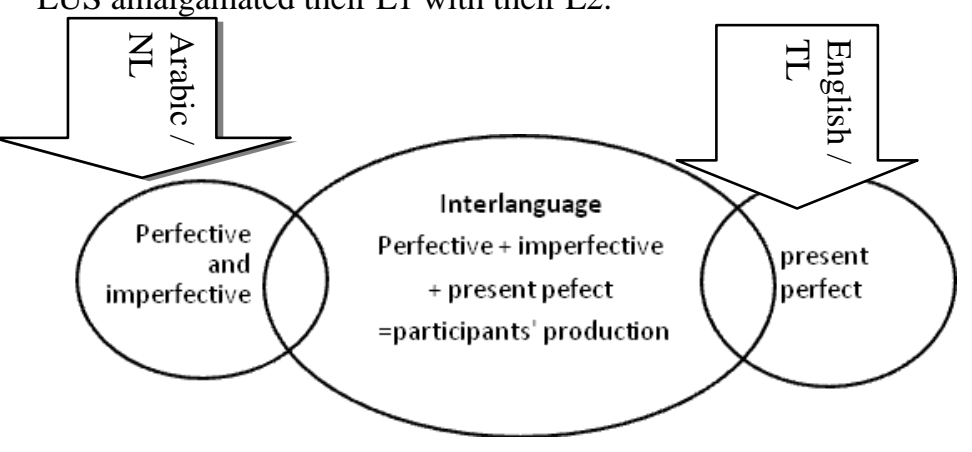

Fig. [1]. Responsibility of Interlanguage

The area in the middle, in Fig. [1], is the interlanguage, which forms the common ground of the NL and TL as presented by [49] and [12]. The area on the left presents the verb classification of the Arabic language NL, and the one on the right displays the present perfect used in the TL based on the instruments in this study. We can see clearly that the Arabic and English areas do not intersect; however, the integration occurs in the interlanguage field in the middle, for it has its own system that combines both the NL and TL and cannot be attributed solely to any one of them.

As shown in the interlanguage area in Figure [1], the participants have neither used exclusively their Arabic verb system, nor the present perfect entirely. The participants used some features from their NL and others from their TL. LUS have followed same erroneous 'systematic error' in all their productions because they are the essential deciders of choosing the best temporal notions to express their thoughts. They produced their own linguistic system. Interlanguage can be further inspected and verified in its five processes demonstrated in the results revealed in this study. The first process is the 'transfer' which has presented itself as an essential witness to the interlanguage responsibility for this unconventional use of tenses versus the present perfect. It is clearly demonstrated in the percentage of simple past prevalence by $56.38 \%$ and the simple present by $26.06 \%$. They fell back into their acquired knowledge from their Arabic grammatical rules in applying English grammatical rules. They internally and subtly mixed them and produced mostly simple tenses rather than present perfect, for their similarity and imminence to their mother language classifications and notions.Moreover, the literature review shows the absence of the commonalities of forms between 
English present perfect and Arabic language verb system which revealed itself clearly in the results.

In brief, the similar elements that exist in the participants' NL as the simple tenses/ perfective and imperfective in Arabic dominate the use of present perfect/ aspect. The high percentage $82.44 \%$. Table $\mathrm{X}$ is an indicator to the inhibitory and subtle transfer done by the participants while producing TL. It cannot be assumed that transfer is the only factor responsible for these results, for such assumption does not serve as a proper justification for the role played by the adverbials especially that Arabic language has adverbials that indicate timing as 'ghadan' which means tomorrow, or 'mundhu' that means since. If transfer is deemed the sole responsible one, we should not have encountered samples using the present perfect properly.

Interlanguage overgeneralization is also responsible for our data. The easiest tenses to learn in the English grammar verb rules are the simple present and the simple past as indicated previously by [16]. LUS have started learning them since the third grade, and they are the most common ones to them. Nevertheless, erroneous production of the simple past and simple present in addition to the absence of considering the adverbials in determining the temporal notion and correct verb form in their writings as shown in TablesIV, VI, VII, VIII, IX, X, XII and XII [reveal that they overgeneralized the easiest rules that they already knowof tenses which scored $82.44 \%$ without regarding the limitations or exceptions of these rules. They used adverbials of present perfect with simple present by a rate of $29.55 \%$ and with simple past by a rate of $61.36 \%$. Odlin [43] refers to these usages as the rules that go beyond the normal rules. Their overgeneralization of tenses directly affected their L2 production as [21] argue. In other words, they produced nonstandard structure and depended on 'overuse' and 'over-indulgence' as mentioned in the literature. Flick's study (1979), as cited in[15], on 20 adults support these results where it revealed that transfer and overgeneralization composed $50 \%$ of the reasons responsible for students' errors. Furthermore, the interlanguage transfer of training indicates to the influence of the educational teaching process and instructors' role in learners' production as [53] indicates. Deductively and based upon the tables' data, we can posit that Lebanese University English instructors and the process of learning are additional factors responsible for such erroneous employment of simple past and simple present instead of the present perfect as indicated in Tables IV, VI, X, XI, and XII. The learners have been learning English for more than 14 years, and still cannot express themselves properly. Moreover, most English language instructors are not native, at least in the first, second, and third level of English at the Lebanese University. In other words, the teachers are also 'transporters' from L1 to L2 and interlanguage might have affected them in the first place. This conclusion is of natural and logical sequence, and, unfortunately, it is hard to inspect every single one of these reasons among the 50 participants.

Interlanguage strategies of second language learning refer to the employed methods, which participants depend on while learning a second language. They contribute to the way the participants employ their first language in order to learn the rules of the second one. Jain (1969), as cited in [49] believes that this happens on the syntactical level. In our study, the participants compared the verbs system of the two languages and what resulted simple present and simple past forms due to their interrelation with the present perfect and accordingly produce interlingual errors. However, reference [49] attributes such reason to the students' tendency to simplify their TL.

Interlanguage strategies of second language communication where students refer to what they know in order to resolve the problems of expressing their ideas when $\mathrm{TL}$ is unequal to the task of NL as [53] indicates. We can conclude that students rely heavily on the simple past and simple present that they relatively know instead of using their present perfect, which is more complicated for them in expressing their opinions and ideas in the writing production. Nonetheless, if they master the exact usage of any of the three tenses, we would not have encountered these high percentages of unconventional usage of the tenses in replacing the present perfect, even with clear adverbs/adverbials or the improper use of the present perfect itself. [14]- [18]consider that students commit such errors while trying to overcome their language barriers. According to [14], it reveals their level of progress, and to [6] it refers to their inability to produce same level of fluency as their L1.

Interlanguage characteristics and variables are also bumped into our study. Stability is encountered when we have a repetition of mistakes for more than one time[49]. This is clearly revealed in the high percentage of repetitive replacement of present perfect by simple past by $68.39 \%$ in producing same errors, and in simple present rate with $26.06 \%$. Sytematicity of learners is clear through recurrent usage of certain forms, mixing rules of tenses, aspectual perfective and adverbials together as clearly indicated in our statistical data.

Mutual intelligibility and backslidingcharacteristics are hard to be inspected in this study. However, backsliding can be only indicated to by the misuse of the present perfect form, such accurate inspection needs longitudinal study. The above verification of Interlanguage, its five psycholinguistic processes and characteristics, data, and graphs serve as a definite answer to the research question number two. They confirm that interlanguage is responsible for the erroneous employment of the present perfect by Lebanese University undergraduates. IL has direct influence in the choices of verbs where Arabic verb system and English verb system are mixed together and produced as one separate unique system by the participants.

The answer to research question number two of L1 subsequent effect is answered and revealed in students' usage of tenses (simple past and simple present) over present perfect (PP) by $82.44 \%$ compared to $17.56 \%$ of the present perfect. The number one dominance and inclination goes to the simple past as indicated in Tables IV, VI, VII, VIII, XIII and notably [XIV]. Its dominance rated $76.26 \%$ compared to PP $23.74 \%$, and $56.38 \%$ overall, while simple present ranked second and dominated the PP by $59.76 \%$ and $26.06 \%$ in general.Lebanese University students have expressed themselves as they know using what is accessible to them 
through the two languages, mixing their native language with their target language. They, in plain English, produced their own separate linguistic system - interlanguage.

The results also conform with a Turkish paper of Licensing of Present Perfect by Turkish Learners by [8] that revealed almost the same findings since Turkish language does not have any similar form of present perfect in its language. The simple past substituted the present perfect. However, in his paper, he attributed his results to negative transfer, which the researcher of this study disagrees. It is true that his students tended to use it more without complete elimination of the present perfect usage. Additionally, the findings of tenses difficulty and replacement of the present perfect also comply with, [47] , and [40]. However, their results are attributed to fossilization rather than to interlanguage processes and characteristics as proven in this study. Not to forget to mention, the new findings of the adverbs negative role has not been mentioned by any of the above studies.

\section{CONCLUSION}

IL has changed the perspective of learning second language.It regards learners as active participants in the educational process with the innate systematization of the rules to produce their own linguistic system while moving toward their TL. The statistical data analysis findings revealed that the proper employment of the present perfect did not exceed $18 \%$, which indicates to the difficulties encountered by students in employing the present perfect and answered research question number one. Interlanguage transfer, overgeneralization, teaching strategies, transfer of teaching, and communication strategies, backsliding, and mutual intelligibility are found as one full parcel that leads to one result: the learners use the language in target-like forms, but not the target-form itself. The unconventional use and non-existence of the present perfect form in Lebanese University undergraduates' samples have managed successfully to prove how interlanguage affected employment of the present perfect in their writings. Learners face a great deal of complexity in using tenses and aspects. If they had mastered any of the simple past, simple present, or present perfect rules, we would not have encountered such high percentage of erroneous employment of the present perfect. Overall assessment would suggest that learners referred to the closest approximation of L1 and L2 combined, as [26] indicates, which in plain English is 'interlanguage'.

The new areas of this study's findings can lie in explaining how the five processes, characteristics and variations of interlanguage are responsible, one by one, not only focusing on the transfer; thus, approaching new aspects for better consideration of the reasons to tackle while teaching English language. It shows in details how the participants follow certain ways of expressing their ideas depending on mixing the two languages. Beyond interlanguage and present perfect observations, this study also finds that learners' dependence on adverbs and adverbials is very limited. Learners do not consider the adverbs of time, which indicate certain temporal notions and specific verb forms. The results of this research conform with many linguists as [39] who regards grammar as an area of complexity to second language learners, in particular, to the Arabic speakers learning English. They postulate that this complexity is evident and exists in the area of aspects and tenses. They emphasize on the reasons related to the teaching process, teaching methods or techniques, lack of a convenient learning environment, lack of learners' motivation, and deficiency in curriculum.

\section{A. Limitation of the Study}

This study is limited to inspecting interlanguage and the effect of L1 grammar rules on the present perfect form in L2. Students' use of the wrong verb 'to have' accorded with the subject or wrong form of past participle is disregarded, for they are not within scope of the study. In addition, the study does not focus on the assumption that semantics effected choice of verb forms by the LU students, which might be a well verified reason beyond this study.Demographic location, social background, cultural background, heterogeneity, and inaccessibility of the populations form variables to generalizability of our study to other Faculties of Sciences. Testing this erroneous production on different proficiency levels of the students would have been insightful. A longitudinal study proposing and testing new methods to correct this erroneous usage would have been also a salient additional value.

\section{B. Pedagogical Recommendations to Reduce Interlanguage Effects Notably of Verb Forms}

This section provides a few recommendations for possible solutions in addition to further insights for future researches.The Literature Review and Discussion Chapters introduced psycholinguistic processes separately but that does not reveal that they come and appear in isolation of each other especially in attributes to their reduction. They, in a whole, form the Interlanguage Hypothesis. The researcher will try to produce general and specific solutions to these five psycholinguistic processes.

- -Accepting Errors and Positive Attitude Vs Interlanguage Processes

- Informing and Motivating Students Vs Interlanguage Processes

- Exposure to Target Language Culture Vs Interlanguage Processes

- Role of Functional Grammar Vs Interlanguage of Syntax

- Strategic Feedback Vs IL Transfer, IL Overgeneralization, and IL L2 Communication.

- Corrective Feedback Vs IL Transfer of Training.

- Teaching Strategies Vs IL Transfer of Training and IL Strategies of Second Language Learning

\section{REFERENCES}

[1] A. AlKasimi, Linguistics and the Bilingual Dictionaries, New York: Leiden E.J. Brill, (1977)

[2] M. H. Al-Khresheh, A review study of interlanguage theory. International Journal of Applied Linguistics and English Literature, vol 4, 2015, pp.123-131,p.128.

[3] M. AlSalmi,Tense and Aspect Acquisition in L2 English by Native speakers of Arabic. AWEJ, vol 4, 2013, pp. 270-282,p. 276. 
[4] G. Anderson,N Arsenault,Fundamentals of Educational Research. Pennsylvania: Tylor \& Francis Group, (1998)

[5] R. E Asher,The Encyclopedia of Language and Linguistics 4. Elmsford, New York: Pergamon Press Inc. pp. 1715-1719.experienced by Arab EFL learners. Advances in Language and Literary Studies, vol 7, 1994, 135-147, p. 196doi:10.7575/aiac.ijalel.v.4n.3

[6] E. Bialystok, Communication Strategies. Oxford: Basil, (1990).

[7] W. R Borg, M. D. Gall,Applying Educational Research: A Practical Guide. Boston: Pearson Education, 1990.

[8] T. Bulut, The licensing of the English present perfect tense by Turkish adults. International Journal of Humanities and Social Science, vol 1, pp. 221-227, 2011.

[9] P. Butler-Tanaka, Fossilization: A chronic conditioner is consciousness-raising the cure? (Unpublished MA Thesis). University of Birmingham, Birmingham, 2000.

[10] L.Cohen, L., Manion,K. Morisson, Research Methods in Education. London and New York: Routeledge Falmer, 2011.

[11] B. Comrie, Aspect. Cambridge: Cambridge University Press, 1976

[12] S. P. Corder, Strategies in Interlanguage Communication. London: Longman. p. 43, p.96, 1983.

[13] N. Diab, The transfer of Arabic in the English writings of Lebanese students, $E S P$, vol 18,1996,pp.71- 83 .

[14] R. Ellis, SLA and language pedagogy. Second Language Acquisition, vol 19, 1997, pp. 69-92. doi:10.1017/s0272263197001058

[15] R. Ellis, Second Language Acquisition. Oxford: Oxford University Press, 2004.

[16] R. Ellis, The study of second language acquisition, Oxford: Oxford University Press, 2008.

[17] M.W. Eysenck, Cognitive Psychology: An International Review, West Sussex, England: John Wiley \& Sons, Ltd,1990, pp. 111

[18] C.Færch, \&G. Kasper, Strategies in Interlanguage Communication. London: Longman, 1983

[19] E. Fauziati, Interlanguage and error fossilization: A study of Indonesian students learning English as a foreign language,Indonesian Journal of Applied Linguistics, vol 1, 2011, 23-38.

[20] I. Feigenbaum, The uses of the English present perfect,Language Learning, vol 31,1981,393- 408.

[21] S.Gass, L. Selinker, Second Language Acquisition: An Introductory Course. New York: Routledge, 2008.

[22] S. Greenbaum, R. Quirk, A Student's Grammar of the English Language, London: Longman Group Ltd, p.53, 1990.

[23] A. Gully, Grammar and Semantics in Medieval Arabic, Richmond: Curzon Press, p.171,1995.

[24] M. S. Haded, Arabic tense and temporal affinity: A semantico-syntactic insight. Muslim Education Quarterly, vol 13, $1996, p p .46-57$.

[25] A. H. Haidar, Science education reform in the UAE: Science Education and Technology, vol 9,2000, pp.257-273 doi.org/10.1023/a:1009447718203

[26] B. Harley, Transfer in the written compositions of French Immersion Students. Applied Linguistics, vol 10,1989,pp. 331-360. doi.org/10.1093/applin/10.3.331

[27] R. K. Harrison, Verb Aspect. Planned Languages, 1996, Retrieved from: http://balance.wiw.org/ jkominek/lojban/9207/msg00039.html

[28] C. Holes, Gulf Arabic,London: Routledge, 1990.

[29] C. Holes, Modern Arabic Structures, Functions and Varieties. London: Longman,p.126, 1995.

[30] N.Kharma, A. Hajjaj, Errors in English among Arabic Speakers: Analysis and Remedy, London: Longman,p.157, 1989.

[31] G. N Leech, Meaning and the English verb. London: Longman. p.35,1971.

[32] B. Mayor, Growing Up with English. In Communicating in English. London: Routledge, 2012.

[33] M. McCarthy, Discourse Analysis for Language Teachers, Cambridge: Cambridge University Press, 1991.

[34] [34] J. McCawley, Grammar and Meaning, New York. Academic Press, 1976.

[35] L. A. Michaelis, Aspectual Grammar and Past-Time Reference, London: Routledge, 1998.

[36] T. F Mitchell, \&S. El-Hassan, Modality, Mood and Aspect in Spoken Arabic (with special reference to Egypt and the Levant). London and New York: Kegan Paul International, 1994.

[37] A. Mourssi, Analyzing interlanguage stages ALEs pass through in the acquisition of the simple past tense. English Language Teaching, vol 5,2012,pp.148-163. doi:10.5539/elt.v5n10p148

[38] L. Mukattash, Contrastive Analysis, Error Analysis and learning difficulty. In Jacek Fisiak ed. Contrastive Linguistics Prospects and Problems. Mouton Publishers, 1980.
[39] L. Mukattash, Persistence of fossilization. IRAL, vol 24, 1986, pp187-203.

[40] A. Nozadze, Dealing with fossilized Errors while teaching grammar. Journal of Education, vol 1,2012, pp.41-46

[41] J. O'Brien, Tense and aspect in the interlanguage of Gulf Arab learners of English (doctoral dissertation). Retrieved from: https://pulsearch.princeton.edu.p. 96, 97, 98, 2003.

[42] T. Odlin, Introduction. Perspectives on Pedagogical Grammar, p.169,1981,1-22. Doi: 10.1017/cbo9781139524605.003.

[43] T. Odlin, Language Transfer. Oxford: Cambridge University Press, 1989.

[44] T. Odlin, Language Transfer: Cross-linguistic Influence in Language Learning. Shanghai: Foreign Language Education Press, (2001).

[45] Percentages Calculator: http://www.had2know.com/education/pie-chart-percentages-calculator $\underline{\mathrm{html}}$

[46] L. Putri, Communication strategies in English as a second language context. Advances in Language and Literary Studies, vol 4,2012, 128-132. doi:10.7575/aiac.alls.v.4n.1

[47] M.Qian, Z. Xiao, Strategies for preventing and resolving temporary fossilization in second language acquisition. CCSE, vol 3,2010, $180-183$

[48] S. Sabbah, Negative transfer: Arabic language interference to learning English. Arab World English Journal (AWEJ), Special Issue on Translation, $\quad$ vol $\quad 4, \quad 2015, \mathrm{pp} .269-288$ doi.org/10.1163/1570-6699_eall_eall_sim_vol2_0026

[49] L. Selinker, Interlanguage. International Review of Applied Linguistics in Language Teaching, vol 10, 1972,209-241.

[50] L. Selinker, M. Swain,G. Dumas, The interlanguage hypothesis extended to children. Language Learning, vol 25, p.141,1975, 139-152. doi.org/10.1111/j.1467-1770.1975.tb00114.x.

[51] E. Tarone, On the variability of interlanguage systems,Applied Linguistics, vol4,1983, 142-164.

[52] E. Tarone, Interlanguage, In Concise encyclopedia of sociolinguistics pp. 475- 81, Oxford: Elsevier, 2001.

[53] E. Tarone, Interlanguage,Encyclopedia of Language \& Linguistics,p. $749, \quad$ p. $749, \quad$ p.119, 2006, pp. 747-752. doi:10.1016/b0-08-044854-2/00618-0,

[54] B. Taylor, The use of overgeneralization and transfer learning strategies by elementary and intermediate students of ESL. Language Learning, vol 25,1975, pp. 73-107.

[55] A. B.Valle, Input and interlanguage: a review of the research,Estudios Ingleses de la Universidad Complutense, vol 6, p. 130, 1998, pp.129-159.

[56] Variables Definition: http://dissertation.laerd.com/extraneous-and-confounding-variables.ph $\mathrm{p}$

[57] V. E Wenzell, Transfer of aspect in the English oral narratives of native Russian speakers, In Transfer in Language Production. New Jersey:Ablex Publication, 1989.

[58] W. Wright, Arabic Grammar, New York. Dover Publications, 2005

[59] G. Yule, Explaining Grammar, Oxford. Oxford University Press.p.51p. $63,2000$.

[60] H. Zobl, (980. Developmental and transfer errors. TESOL Quarterly, vol 14,1980, pp. 469-479.

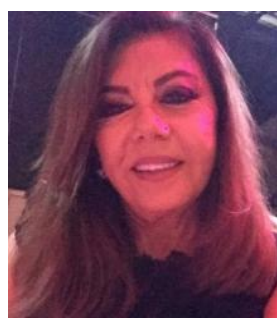

Mona Mohamad Taher Tahseldar was born on June 1st, 1955 in Tripoli,Lebanon. She graduated with a BA in English literature from DamascusUniversity in 1980. Then, got her English education MA in 1994 and PHD in 2007 from USJ University. Mona has been an associate professor at the Lebanese University, faculty of educationsince 2007.Tahseldar is a an active researcher in Linguistics and didactics with many publications.

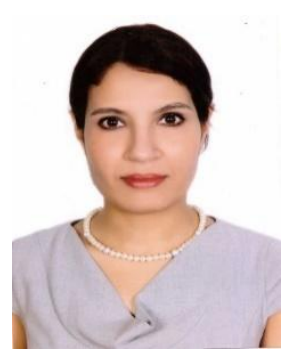

Yousra SABRA is an associate Professor at the Lebanese University and an educational counselor at the Lebanese Ministry of Education. She is also a qualified university professor in linguistics according to the French government, CNU. Dr. SABRA is an active researcher in the field of contrastive and applied linguistics as well as didactics. She has several publications in these areas in English and French published online and she is a co-author of the educational series, 
Central Themes, dedicated to teaching English at high school level, World Heritage Publishers. She is also member of the reading committee of the international journal Modèles Linguistiques in addition to active membership in other educational organizations (AIPL and BABEL).

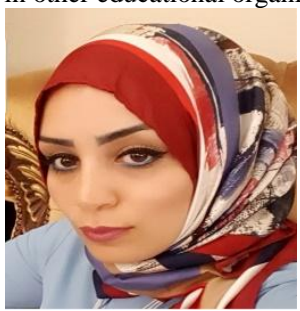
Soha Zouheir KANSO, Ph.D candidate at the Lebanese University. She has been an instructor of English Language for 20 years and at Center of Language at Lebanese University, Faculty of Sciences for the last 7 years. She has also a B.A in languages and Translation. She is a sworn translator. 